\title{
Comparison between eddy covariance and automatic chamber techniques for measuring net ecosystem exchange of carbon dioxide in cotton and wheat fields
}

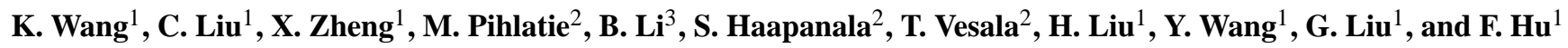 \\ ${ }^{1}$ State Key Laboratory of Atmospheric Boundary Layer Physics and Atmospheric Chemistry, Institute of Atmospheric \\ Physics, Chinese Academy of Sciences, Beijing 100029, China \\ ${ }^{2}$ Department of Physics, University of Helsinki, P.O. Box 48, Helsinki 00014, Finland \\ ${ }^{3}$ Department of Soil and Water Sciences, China Agricultural University, Beijing 100094, China
}

Correspondence to: X. Zheng (xunhua.zheng@post.iap.ac.cn)

Received: 7 March 2013 - Published in Biogeosciences Discuss.: 22 May 2013

Revised: 6 September 2013 - Accepted: 9 September 2013 - Published: 2 November 2013

\begin{abstract}
Static and transparent automatic chamber (AC) technique is a necessary choice for measuring net ecosystem exchange (NEE) of carbon dioxide $\left(\mathrm{CO}_{2}\right)$ in circumstances where eddy covariance (EC) technique is not applicable. However, a comparison of the two techniques for measurements on croplands has seldom been undertaken. We carried out NEE observations in a cotton field (for one year) and a winter wheat field (for one cropping season) using both $\mathrm{AC}$ and EC techniques, to (a) compare the NEE fluxes measured using each technique, and (b) test the NEE measurement performance of an automatic chamber system (AMEG), which was designed for simultaneous flux measurements of multiple gases. The half-hourly NEE fluxes measured with the two techniques were in approximate agreement, with the AC fluxes being 0.78 (cotton) and 1.06 (wheat) times the size of the EC fluxes. When integrated to daily timescale, the fluxes of the two techniques were in better agreement, showing an average ratio of 0.94 and 1.00 for the cotton and wheat, respectively. During the periods with comparable field conditions and normal performance of both instruments, the cumulative NEE fluxes revealed small differences between the two techniques $(-9.0 \% \sim 7 \%$, with a mean of $0.1 \%$ ). The measurements resulted in an annual cumulative NEE of $-40 \mathrm{~g} \mathrm{C} \mathrm{m}^{-2} \mathrm{yr}^{-1}$ (EC) and $-42 \mathrm{~g} \mathrm{C} \mathrm{m}^{-2} \mathrm{yr}^{-1}$ (AC) in the cotton field, and a seasonal cumulative NEE of $-251 \mathrm{~g} \mathrm{C} \mathrm{m}^{-2}$ (EC) and $-205 \mathrm{~g} \mathrm{C} \mathrm{m}^{-2}$ (AC) in the wheat field. Our results indicate that, for cropland populated by short plants, the AMEG system and the data processing procedures applied in this study are able to provide NEE estimates comparable to those from EC measurements.
\end{abstract}

\section{Introduction}

The net ecosystem exchange (NEE) of carbon dioxide $\left(\mathrm{CO}_{2}\right)$ is the difference between carbon assimilation by photosynthesis and $\left(\mathrm{CO}_{2}\right)$ release via ecosystem respiration. $\mathrm{CO}_{2}$ uptake by the ecosystem is represented by a negative flux and $\mathrm{CO}_{2}$ loss is represented by a positive flux (e.g., Chapin III et al., 2006). Direct observation of the NEE is a very important step in the quantification of the carbon source or sink flux of a terrestrial ecosystem.

There are two main approaches for measuring NEE fluxes: the eddy covariance (EC) technique and the chamber technique. Each of them has advantages and disadvantages. The EC technique is based on micrometeorological theories. It allows for continuous and non-disturbing measurements and provides spatially averaged fluxes on a scale of a few hectares to several square kilometers (Baldocchi, 2003). It has been widely used in different ecosystems (e.g., Goulden et al., 1996; Lafleur et al., 1997; Miyata et al., 2000). However, there are limitations to its applicability for small-scale field plots and complex terrains due to its theoretical assumptions (Lee et al., 2004). In addition, due to extensive quality checks, data gaps are inevitable with EC measurements, particularly under low-turbulence mixing conditions (Foken and Wichura, 1996). The technique of static chamber in combination with a close-path gas analyzer can also be used for NEE measurement in ecosystems with low-stature canopies, such as grasslands and croplands (e.g., Maljanen et al., 2001; Steduto et al., 2002; Langensiepen et al., 2012). The chamber technique offers the advantages of being lower in cost 
and simple in principle. Also the chambers are portable and well-suited for small-scale (e.g., $10^{2}-10^{4} \mathrm{~m}^{2}$ ) studies. In this regard, the chamber technique is appropriate for replicated measurements in multiple small plots of field trails, which are absolutely necessary for identifying the impacts of natural or anthropogenic driving forces upon the NEE and thus the net ecosystem carbon balance. However, chamber measurements are prone to a variety of potential errors, such as modifications in the enclosed microclimate, pressure artifacts, and spatial heterogeneity (Livingston and Hutchinson, 1995; Welles et al., 2001; Davidson et al., 2002). These drawbacks have limited the application of the chamber technique for NEE measurements; nevertheless, it is an alternative method that can be used when the EC method is not suitable (e.g., Burkart et al., 2007).

Studies comparing the NEE fluxes measured using the EC and chamber techniques are necessary to highlight the potential sources of errors and to test the reliability of chamber fluxes. To date, however, only a few researchers have conducted comparison studies. Laine et al. (2006) found that the two techniques had good agreement in measuring the NEE fluxes in a peatland. In a scrub-oak ecosystem, Dore et al. (2003) reported that the NEE fluxes measured by the chambers were generally higher than those measured by the EC by $8-26 \%$. A study by Fox et al. (2008) found an even larger (up to $60 \%$ ) difference between the two techniques in a heterogeneous Arctic tundra site, for which the difference depended on the upscaling approaches of the chamber measurements. However, comparison studies, especially on the croplands, are still lacking.

Simultaneous measurements are required to quantify the aggregate emissions of multiple greenhouse gases $\left(\mathrm{CO}_{2}\right.$, $\mathrm{CH}_{4}$, and $\mathrm{N}_{2} \mathrm{O}$ ) and the fluxes of other gas species (like nitric oxide) and to investigate how their relationships vary with environmental factors and management practices. An instrumental system, automatic chamber measuring system for emissions of carbon and nitrogen trace gases (AMEG), was designed to meet these requirements. The system was based on the static, transparent automatic chamber (AC) technique. The AMEG had been proven able to measure the $\mathrm{N}_{2} \mathrm{O}$ fluxes successfully from cotton and wheat fields (Liu et al., 2010, 2011, 2012; Wang et al., 2013) but its performance for measuring the fluxes of NEE and other gas species still needed to be tested prior to this study.

In this study, we attempted to compare the AC and EC techniques for measuring NEE fluxes from croplands in which cotton and winter wheat are cultivated. The comparison was undertaken to (a) assess the reliability of chamber NEE measurements on cropland ecosystems with suitable plant heights for chamber application and (b) test the performance of the AMEG system for measuring NEE fluxes.

\section{Materials and methods}

\subsection{Site description and agronomic management}

The experimental site $\left(34^{\circ} 55^{\prime} 30^{\prime \prime} \mathrm{N}, 110^{\circ} 42^{\prime} 35^{\prime \prime} \mathrm{E}\right)$ was located in a western suburb of Yuncheng city, Shanxi Province, China. This region is subject to a warm temperate continental monsoon climate. From 1998 to 2008, the annual mean air temperature and annual mean precipitation were $14.7^{\circ}$ and $508 \mathrm{~mm}$, respectively (National Meteorological Information Center of China Meteorology Administration, http: //cdc.cma.gov.cn). The dominating wind directions at the site were from east or from west (Wang et al., 2013). The surface soil $(0-6 \mathrm{~cm})$ had a pH of 8.7 (water extract). More details of the soil properties and environmental characteristics of the site were described by Liu et al. $(2010,2011)$.

The field layout and instrument locations are shown in Fig. 1. A 5-m-wide path divided the experimental site into the cotton area (south) and the wheat area (north). A temporary laboratory (length $\times$ width $\times$ height $=5 \mathrm{~m} \times 2 \mathrm{~m} \times 2.5 \mathrm{~m}$ ) was built on the path; here the gas samples from the chambers were analyzed. The automatic chambers for the measurements in the cotton and wheat fields were situated south and north of the lab house, respectively. The EC systems in the cotton and wheat fields were both located $60 \mathrm{~m}$ away from the border of the two areas. Four manual chambers were installed near the automatic chambers for intermittent measurements during the non-growing season of the cotton field.

In the southern area, cotton had been cultivated continuously since 2004. On 6 November 2008, the cotton residue from the previous growing season was cut into pieces and plowed into the soil by machine at depths of $0-30 \mathrm{~cm}$. The field was then fallow until cotton was sown on 10 April 2009. The cotton seeds were sown by machine with row spacing of $80 \mathrm{~cm}$. Fertilizer was applied on 28 June 2009 at rates of $75 \mathrm{~kg} \mathrm{~N}$ (90\% urea, $10 \%$ di-ammonium phosphate), $9 \mathrm{~kg}$ P, and $10 \mathrm{~kg} \mathrm{~K}$ per ha. The field was sprinkled with underground water on 8 April $(36.5 \mathrm{~mm}), 10$ July $(85.3 \mathrm{~mm})$ and $21 \mathrm{Au}-$ gust $2009(28.7 \mathrm{~mm})$. The mature cotton seeds and cotton fibers were manually harvested on 1, 10, and 23 September and 5 October. All of the residue that remained in the field was incorporated into the soil later.

In the northern area, winter wheat and summer maize had been cultivated in rotation since 2005. Our comparison study was conducted only in wheat season. On 18 October 2009, the maize straws of the previous growing season were cut off and plowed into the soil at depths of $0-20 \mathrm{~cm}$ in the area of the automatic chambers and $0-5 \mathrm{~cm}$ in the ambient area. The difference in the depths resulted from malfunction of the machine used for deep plowing. The wheat seeds were sown on 19 October at a row spacing of $20 \mathrm{~cm}$. Fertilizers were applied at rates of $60 \mathrm{~kg} \mathrm{~N}$ (urea), $60 \mathrm{~kg} \mathrm{P}$ and $30 \mathrm{~kg} \mathrm{~K}$ per ha before sowing (18 October 2009) and $120 \mathrm{~kg} \mathrm{~N}$ (urea) per ha in the spring (18 March 2010). The field was irrigated on 


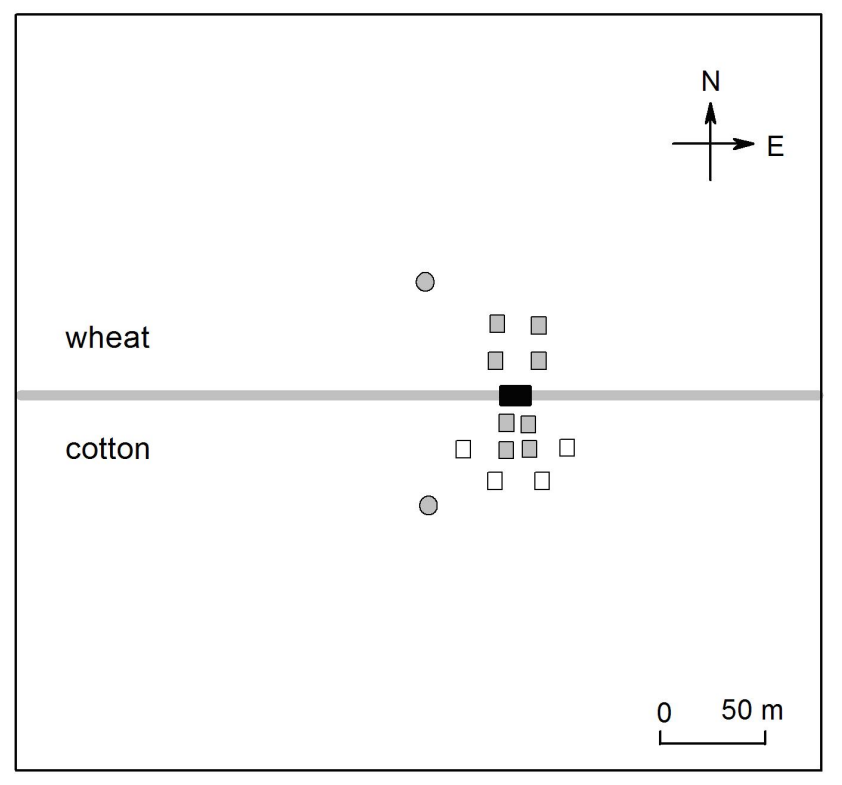

Fig. 1. Layout of the experimental site. The horizontal course line indicates the path dividing the experimental area into the cotton (north) and wheat (south) fields. The grey circles, grey squares, and empty squares indicate the locations of the eddy covariance towers, automatic chambers, and the manual chambers, respectively. The black rectangle indicates the location of the temporary laboratory.

9 January, 23 March, 10 April and 4 May 2010. The wheat was harvested on 13 June 2010.

\subsection{Eddy covariance measurements and data processing}

\subsubsection{Instrumentation}

The NEE measurements using the EC method were conducted from 8 November 2008 to 7 November 2009 in the cotton field and from 21 October 2009 to 13 June 2010 in the wheat field. During the cotton measurement period, the $\mathrm{CO}_{2}$ concentration was measured with an open-path infrared gas analyzer (LI-7500, LI-COR Inc., USA); the wind velocities in three dimensions were measured with a CSAT-3 sonic anemometer (Campbell Scientific Inc., USA) from 7 November 2008 to 13 January 2009 and a USA-1 anemometer (METEK GmbH, Germany) from 14 January 2009 to 15 October 2009. During the wheat measurement period, a LI-7500 analyzer and a CSAT-3 anemometer were used. The sensors of each EC system were installed $2 \mathrm{~m}$ above the ground. The raw data were saved on a CR5000 data logger (Campbell Scientific, Inc., USA) at a frequency of $10 \mathrm{~Hz}$. The detection limit of the EC system was estimated to be $0.001 \mathrm{mg} \mathrm{C} \mathrm{m}^{-2} \mathrm{~s}^{-1}$ following the equation in Wang et al. (2013).

\subsubsection{Flux calculation}

The NEE fluxes from EC measurements $\left(\mathrm{NEE}_{\mathrm{ec}}\right)$ were determined using Eq. (1) (Lee et al., 2004), where $F_{\text {ec }}$ is the turbulent flux and $F_{\mathrm{S}}$ is the storage flux. The former term was calculated following Eq. (2), where $\rho$ denotes the density of the air $\left(\mathrm{g} \mathrm{m}^{-3}\right), w^{\prime}$ and $c^{\prime}$ denote the instantaneous deviations of the vertical wind velocity $\left(\mathrm{m} \mathrm{s}^{-1}\right)$ and $\mathrm{CO}_{2}$ concentration $\left(\mu \mathrm{mol} \mathrm{mol}^{-1}\right)$ from the mean values, respectively, and the overbar indicates time averaged over $30 \mathrm{~min}$.

$\mathrm{NEE}_{\mathrm{ec}}=F_{\mathrm{ec}}+F_{\mathrm{s}}$

$F_{\mathrm{ec}}=\rho \overline{w^{\prime} c^{\prime}}$

Before calculating $F_{\mathrm{ec}}$, spikes in the raw data time series were removed following Vickers and Mahrt (1997), and gaps were filled by interpolating valid data points. The double rotation method (Kaimal and Finnigan, 1994) was performed on the wind components so that the mean vertical wind velocity was reduced to zero for each half-hour period. The raw turbulent fluxes were corrected for the spectral loss (Moore, 1986) and the density fluctuations caused by correlated heat and water vapor fluctuations (WPL-correction) (Webb et al., 1980). The storage flux $\left(F_{\mathrm{s}}\right)$ resulting from changes in the $\mathrm{CO}_{2}$ concentration in the air column below the measurement height was computed using the single point method (Hollinger et al., 1994).

The calculated $\mathrm{NEE}_{\mathrm{ec}}$ were quality controlled using the following four steps. First, the fluxes during episodes of precipitation and sprinkler irrigation were discarded. Second, in the nighttime or during fallow periods, $\mathrm{NEE}_{\mathrm{ec}} \mathrm{s}$ smaller than $-0.001 \mathrm{mg} \mathrm{C} \mathrm{m}^{-2} \mathrm{~s}^{-1}$ (the lower detection limit of EC) were rejected. Third, the stationarity and integral turbulence characteristic tests (Foken and Wichura, 1996) were applied, and quality flags from 1 to 9 were assigned to each half-hourly flux; the fluxes flagged with 4-9 were regarded as bad data. Finally, to ensure that the measured fluxes were representative of the exchange rate of the fields of interest, an analytical footprint model (Horst and Weil, 1994) was used to investigate the flux source area; the fluxes were rejected if the contribution from the field of interest was less than $80 \%$.

\subsubsection{Estimation of cumulative flux}

Gap-filling was performed to obtain the cumulative EC fluxes. The data gaps less than four hours were directly filled by linear interpolation. Larger gaps were filled using empirical models based on Eqs. (3-5) when meteorological data were available, and using the mean diurnal variation method (Falge et al., 2001) when it was not.

The NEE was defined as the relationship between the residual ecosystem respiration (ER) and photosynthesis (i.e., gross primary productivity, GPP), as described by Eq. (3) (e.g., IPCC, 2006).

$\mathrm{NEE}=\mathrm{ER}-\mathrm{GPP}$ 
Data gaps in the nighttime or during fallow periods were filled using the exponential relationship (Eq. 4) between ER and temperature ( $T$ ) (Lloyd and Taylor, 1994), as ER was equal to NEE in these cases. In Eq. (4), $a$ and $b$ are fitting parameters, and $T$ denotes temperature $\left(T_{\mathrm{S}}\right)$ of soil at $5 \mathrm{~cm}$ depth during the fallow periods and air temperature $\left(T_{\mathrm{a}}\right)$ during the vegetation periods. The daytime NEE gaps during the vegetation periods were filled using the residual daytime ER and the GPP, which were estimated using Eqs. (4) and (5) (Falge et al., 2001; Zheng et al., 2008a), respectively. In Eq. (5), PAR is the photosynthesis active radiation $\left(\mu \mathrm{mol}\right.$ photon $\left.\mathrm{m}^{-2} \mathrm{~s}^{-1}\right), \alpha$ is the apparent quantum yield (mg C $\mu \mathrm{mol}^{-1}$ photon), and GPP ${ }_{\max }$ is the maximum assimilation rate $\left(\mathrm{mg} \mathrm{C} \mathrm{m}^{-2} \mathrm{~s}^{-1}\right)$ at saturation PAR.

$\mathrm{ER}=a \cdot \exp (b \cdot T)$

$\mathrm{GPP}=\frac{\alpha \cdot \mathrm{PAR} \cdot \mathrm{GPP}_{\max }}{\alpha \cdot \mathrm{PAR}+\mathrm{GPP}_{\max }}$

As the parameters in Eqs. (4) and (5) varied in time due to seasonal changes in crop biomass and soil microbial activity, the cotton and wheat measurement periods were both partitioned into sub-periods according to environmental condition and/or crop growth stage. The sub-periods were defined as two weeks and one month during the vegetation and the fallow periods, respectively. The aforementioned fittings and gap-fillings were performed for each sub-period.

\subsection{Chamber measurements and data processing}

\subsubsection{Instrumentation}

Continuous NEE measurements were performed from 8 November 2008 to 15 October 2009 in the cotton field and from 21 October 2009 to 13 June 2010 in the wheat field, using the AMEG system based on the AC technique. The system consists of a close-path infrared $\mathrm{CO}_{2} / \mathrm{H}_{2} \mathrm{O}$ gas analyzer (LI-6262, LI-COR Inc., USA), twelve transparent chambers, a control unit, and the tubing system. Four chambers were used for the NEE measurement of this study, and the remaining ones were used for other experiments being carried out nearby. The chambers were installed at random in either the cotton or the wheat field, within an area of approximately $300 \mathrm{~m}^{2}$ (Fig. 1). The chambers in the cotton field and the chambers in the wheat field were connected with the LI-6262 in the lab by $28 \mathrm{~m}$ and $48 \mathrm{~m}$ Teflon tubes (inner diameter: $2.17 \mathrm{~mm}$ ), respectively. The chambers were designed with different dimensions to adapt to different crops. Each chamber in the cotton field covered an area of $0.9 \times 0.9 \mathrm{~m}^{2}$ and had optional heights of $0.45 \mathrm{~m}$ ( 8 November $2008-15$ June 2009) and $0.9 \mathrm{~m}$ (15 June-15 October 2009). Chambers for the wheat measurement had a height of $0.9 \mathrm{~m}$ and covered an area of $0.7 \times 0.7 \mathrm{~m}^{2}$. The chamber frame was enclosed by polycarbonate boards (thickness: $1 \mathrm{~mm}$ ), which had a transmittance rate of $90 \%$ for visible and near-infrared radiation.

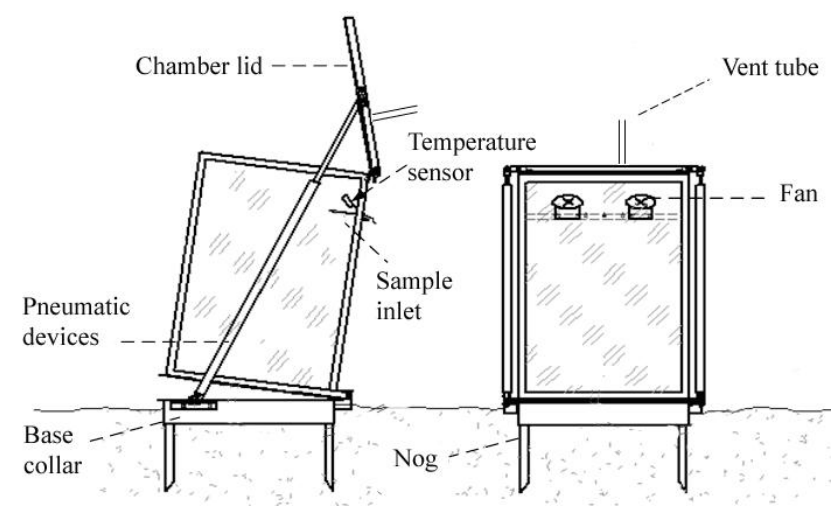

Fig. 2. Schematic illustration of the automatic chambers.

Two mini-fans (12V DC) were installed in the chamber to mix the headspace air during sampling. A vent tube was installed on the chamber lid to maintain the pressure balance between the inside and outside. Each chamber was fixed to a square stainless steel base collar that was inserted $20 \mathrm{~cm}$ into the soil. In the cotton field, each chamber enclosed four plants according to the field density of $\sim 5$ plants per $\mathrm{m}^{2}$. In the wheat field, each base collar was placed across three rows of wheat with a row spacing of $\sim 23 \mathrm{~cm}$. The following procedures were adopted to minimize the chamber's effects on the inside microclimate, the plant growth, and thus the measured fluxes. First, the chambers were designed to leave an open space between the chamber and the ground when the chamber lid was open during measurement intervals; this improved the air exchange between inside and outside (Fig. 2). Second, each chamber was switched between two base collars every week (growing period) or every month (fallow period). Third, whenever a difference of plant growth between inside and outside was visible, the base collars and the chambers were moved to new locations nearby. Only one chamber was closed for sampling each hour. The four chambers were closed in sequence, and a measurement cycle was completed every four hours. Therefore, each chamber provided six flux data each day.

An automatic chamber enclosure lasted for $36-42 \mathrm{~min}$. The first 2 min were used for the NEE measurement, while the rest of the period was used to collect data for $\mathrm{CH}_{4}, \mathrm{~N}_{2} \mathrm{O}$ and nitric oxide measurements (Liu et al., 2010, 2011, 2012; Wang et al., 2013). During the first 2 min period, the air samples were drawn from the chamber headspace using a vacuum pump (N89KNE, KNF, Germany) and transported to the LI-6262 at a flow rate of $600 \mathrm{~mL} \mathrm{~min}^{-1}$ through the Teflon tubes. The samples were analyzed every $5 \mathrm{~s}$. The $\mathrm{CO}_{2}$ signals were recorded in voltages and converted to concentrations using monthly calibration curves, which were derived from six standard gases with concentrations ranging from 0 to $1000 \mu \mathrm{mol} \mathrm{mol}-1$.

During the fallow period of the cotton field, soil $\mathrm{CO}_{2}$ effluxes were manually measured every week using four 
static opaque chambers (Fig. 1). Five gas samples were collected during each enclosure period at intervals of 6-10 min and were analyzed using a gas chromatograph (HP5890, Hewlett-Packard Inc., USA). A detailed description of the sampling operation and instrumental configurations is provided in Zheng et al. (2008b) and Wang et al. (2013).

\subsubsection{Flux calculation}

The NEE fluxes from the automatic and manual chamber measurements $\left(F\right.$, in $\mathrm{mg} \mathrm{C} \mathrm{m}^{-2} \mathrm{~s}^{-1}$ ) were calculated using the following equation:

$$
F=\frac{\mathrm{d} C / \mathrm{d} t \cdot \rho \cdot h \cdot T_{0} \cdot P \cdot 10^{-3}}{T \cdot P_{0}}
$$

, where $\mathrm{d} C / \mathrm{d} t$ is the initial change rate of $\mathrm{CO}_{2}$ concentration $\left(\mu \mathrm{mol} \mathrm{mol}^{-1}\right)$ during the chamber enclosure, $h$ is the chamber height $(\mathrm{m}), \rho$ is the $\mathrm{CO}_{2}$ density $\left(\mathrm{g} \mathrm{C} \mathrm{m}^{-3}\right)$ under standard atmospheric conditions $\left(T_{0}=273 K, P_{0}=1013 \mathrm{hPa}\right)$, $T$ is the air temperature $(\mathrm{K})$, and $P$ is the pressure $(\mathrm{hPa})$ of the chamber headspace. The $\mathrm{d} C / \mathrm{d} t$ was determined using either the nonlinear or the linear method described by Wang et al. (2013), in which this scheme was used to calculate the nitrous oxide fluxes. The term $\mathrm{d} C / \mathrm{d} t$ was treated as three times the precision $\left( \pm 0.1 \mu \mathrm{mol} \mathrm{mol}^{-1}\right.$ at response time of $5 \mathrm{~s}$ ) of the LI-6262 by assuming a noise-to-signal ratio of 3. In this study, $\mathrm{d} C / \mathrm{d} t$ of each $\mathrm{AC}$ measurement was derived from the 12 concentration data measured during the second minute of each enclosure period. The data measured during the first minute were discarded due to the time lag induced by the tubing system. We only accepted fluxes for which there was a significant correlation between the $\mathrm{CO}_{2}$ concentration and the enclosure time $(p<0.05)$. Using Eq. (6), the flux detection limits of the $\mathrm{AC}$ system were estimated at \pm 0.002 and $\pm 0.004 \mathrm{mg} \mathrm{C} \mathrm{m}^{-2} \mathrm{~s}^{-1}$ for the $45-\mathrm{cm}$ and $90-\mathrm{cm}$ high chambers, respectively.

To obtain the final fluxes $\left(\mathrm{NEE}_{\mathrm{ac}}\right)$, two correction steps were applied to the raw $\mathrm{AC}$ fluxes $\left(F_{\mathrm{ac}}\right)$. The first one was performed to correct the biases in the ER and GPP components caused by the differences in temperature and PAR, respectively, between inside and outside the chamber. This step was carried out by taking two correction terms, $\triangle E R$ and $\Delta \mathrm{GPP}$, into account following Eqs. (7-9), where $f$ is a function of temperature based on Eq. (4), $g$ is a function of PAR based on Eq. (5), and the subscripts "out" and "in" denote outside and inside the chambers, respectively. The PAR $\mathrm{R}_{\text {in }}$ was estimated with the $\mathrm{PAR}_{\text {out }}$ and the transmittance rate $(90 \%)$ of visible light through the chamber walls. The parameters in both functions for each chamber during each sub-period were obtained from the fittings according to Eqs. (4) and (5). The second correction was performed to correct the housing effect caused by the chambers during the fallow period, as the long-term use of the automatic chamber over a surface of bare soil would possibly introduce bias in the measured fluxes. This step was conducted by adding a coefficient, $c$, to Eq. (7). The value of $c$ was determined by the ratio of the monthly mean manual-chamber fluxes to the monthly mean AC fluxes corrected after the earlier steps. During the fallow period of cotton, $c$ ranged from 0.45 to 0.79 , with a mean value of 0.61 . This correction was not performed, and thus, $c$ was set as 1.0 during the vegetation period.

$$
\begin{aligned}
& \mathrm{NEE}_{\mathrm{ac}}=c \cdot\left(F_{\mathrm{ac}}+\Delta \mathrm{ER}-\Delta \mathrm{GPP}\right) \\
& \Delta \mathrm{ER}=f\left(T_{\text {out }}\right)-f\left(T_{\text {in }}\right) \\
& \Delta \mathrm{GPP}=g\left(\mathrm{PAR}_{\text {out }}\right)-g\left(\mathrm{PAR}_{\text {in }}\right)
\end{aligned}
$$

\subsubsection{Estimation of cumulative flux}

Because the AC fluxes were calculated with the data gathered during the second minute of each enclosure period, they were regarded as the NEE for the corresponding half hour. Thereafter, each AC flux was referred to as a half-hourly flux. To obtain the cumulative fluxes of individual chambers, the data gaps were filled as described below.

The regular gaps within each measurement interval (length $=3.5 \mathrm{~h}$ ) were filled using linear interpolation, as each chamber was designed to provide a NEE flux every four hours. If the half-hourly flux was very close to the detection limit of the AC system, the missing measurements before or after it were filled with a random number between zero and the detection limit. In particular, this treatment was applied to the measurement gaps in the nighttime of cold winter, when the actual fluxes were very small. Data gaps larger than $4 \mathrm{~h}$ were filled in using the empirical models used to fill in the EC gaps.

There were two big gaps in the cotton data, one from 25 April to 22 July, and one from 16 October to 7 November. The two gaps are referred to as $\mathrm{C} 2$ and $\mathrm{C} 4$, respectively. Thus, the periods before and between them are called $\mathrm{C} 1$ (8 November 2008-24 April 2009) and C3 (23 July-15 October 2009). To obtain the annual NEE, the cumulative fluxes of $\mathrm{C} 2$ and $\mathrm{C} 4$ were roughly estimated. Gap C 2 was caused by a malfunction of the LI-6262 analyzer. It encompassed the seedling stage and the fast-growth stage of the cotton. Gap $\mathrm{C} 4$ occurred during the maturity stage with relatively stable aboveground biomass. Different gap-filling strategies were applied to the three stages.

The gaps during the seedling and maturity stages were filled using the arithmetic means of the results simulated by two models. One model was a function of soil temperature (Eq. 4), in which the parameters were obtained by fitting the soil $\mathrm{CO}_{2}$ effluxes and soil temperature during the fallow period. The other model was a function of air temperature and PAR (Eqs. 3-5), in which the parameters were obtained from the nearest 10 days' measurements. We also employed the second empirical model to fill the gaps during the fastgrowth stage. Considering that the aboveground biomass increased quickly during the seedling and fast-growth stages, 
the NEE fluxes were divided by the aboveground biomass when applying the fittings of the second model. As a result, the modeled results needed to be multiplied by the aboveground biomass of the corresponding gap days. The aboveground biomass data used in this step were modeled with a growth curve function, based on the weekly measurements at the ambient fields.

Due to the fact that the tillage depth at the chamber locations was different from that at the ambient field, we divided the entire wheat season into periods W1 (21 October30 November 2009) and W2 (1 December 2009-13 June 2010), assuming that the effects of tillage difference only impacted period $\mathrm{W} 1$.

\subsection{Auxiliary measurements}

The incoming PAR and global radiation were measured every half hour using a quantum sensor (LI-190SA, LI-COR Inc., USA) and a pyranometer (CM 6B, Kipp \& Zonen, The Netherlands), respectively. The air temperature at a height of $2 \mathrm{~m}$ was recorded every half hour using a Vaisala probe (HMP45C, Vaisala, Finland). The field soil temperature was measured every $10 \mathrm{~min}$ using a TidbiT temperature data logger (Onset, USA) at a depth of $5 \mathrm{~cm}$. The air and soil $(5 \mathrm{~cm}$ depth) temperatures inside the chambers were logged every 1 min using thermocouples (JWB series, Kunlun Coast Sensing Technology Center, Beijing, China). A tipping bucket rain gauge was used to measure hourly precipitation. The volumetric moisture of the top $6 \mathrm{~cm}$ of soil was manually measured every day during the non-frozen period with a portable probe (ML2x, Delta-T Devices, UK), and every day during the frozen period with the gravimetric method. The measured volumetric moisture was converted to the waterfilled pore space (WFPS) using a theoretical particle density of $2.65 \mathrm{~g} \mathrm{~cm}^{-3}$ and a soil bulk density of $1.20 \mathrm{~g} \mathrm{~cm}^{-3}$ (cotton) or $1.17 \mathrm{~g} \mathrm{~cm}^{-3}$ (wheat).

The aboveground biomasses of cotton and wheat in the ambient area were measured at intervals of 7-10 days. In the cotton field, six consecutive plants in the same row were sampled each time. In the wheat field, the plants within an area of $0.6 \mathrm{~m} \times 0.6 \mathrm{~m}$ were destructively sampled at three different locations each time. All samples were oven-dried at $80^{\circ} \mathrm{C}$ for $48 \mathrm{~h}$ and weighed afterwards. The biomass per unit area was then determined using the field density of the cotton plants $\left(\sim 5\right.$ plants per $\left.\mathrm{m}^{2}\right)$ and the row spacing of the wheat field $(\sim 23 \mathrm{~cm})$.

\subsection{Uncertainty and statistical analysis}

We investigated the different sources of uncertainties that affected the calculated EC and AC fluxes. The uncertainties can be divided into two categories: random and systematic.

The random uncertainties in the EC fluxes were estimated to be the differences between the observed fluxes and the modeled values according to Eqs. (3-5) (Aurela et al., 2002).
The systematic uncertainties were estimated with the magnitudes of the energy balance deficits (e.g., Sottocornola and Kiely, 2005; Mauder et al., 2013).

The magnitudes of the random uncertainties in the halfhourly AC NEE $\left(u_{\mathrm{hh}}\right)$ were considered to be equal to the instrumental detection limit. The random uncertainties in the daily AC fluxes $\left(u_{\text {day }}\right)$ of individual chambers were estimated using Eq. (10), where $\lambda$ is the number of valid half-hourly fluxes (varying between 0 and 6) each day, $u_{\text {gap }}$ is the uncertainties in each gap-filled datum, and $u_{\mathrm{sv}}$ is the coefficient of variation $(\mathrm{CV})$ of the daily NEE among the four chambers. For the regular gaps, $u_{\text {gap }}$ was equal to $u_{\mathrm{hh}}$, while for other gaps, $u_{\text {gap }}$ was estimated to be the difference between the observed AC fluxes and the modeled values based on Eqs. (3-5). The random uncertainties in the cumulative NEE of a given period $\left(u_{\mathrm{p}}\right)$ were propagated from the daily uncertainties computed in Eq. (11), where $N$ denotes the number of days.

$u_{\text {day }}=\sqrt{\frac{\sum_{i=1}^{\lambda}\left[\left(u_{\mathrm{hh}}\right)_{i}\right]^{2}+\sum_{j=1}^{48-\lambda}\left[\left(u_{\mathrm{gap}}\right)_{j}\right]^{2}}{4}+u_{\mathrm{sv}}^{2}}$

$u_{\mathrm{p}}=\sqrt{\sum_{i=1}^{N}\left[\left(u_{\text {day }}\right)_{i}\right]^{2}}$

The chamber fluxes were prone to systematic errors due to a failure in detection of the nonlinearity of the $\mathrm{CO}_{2}$ concentration. This underestimation occasionally occurred in our study due to the limited number of $\mathrm{CO}_{2}$ data points $(n=12)$ during the short enclosure period (1 $\mathrm{min})$. For these cases, the flux calculation had to be performed using the linear method. We investigated the differences in the fluxes determined by the nonlinear and linear procedures as well as the frequency of the cases that failed to detect the nonlinearity, and the systematic underestimation was calculated by multiplying these two estimates.

Linear regressions between the $\mathrm{EC}$ and $\mathrm{AC}$ fluxes were applied to compare the EC and AC methods. All fittings following the equations given above were performed using Matlab 7.8 (MathWorks Inc., USA). The Origin 8.0 software package (Origin Lab Ltd., Guangzhou, China) was used for graphical outputs.

\section{Results}

\subsection{Environmental conditions and aboveground biomass}

The radiation data were integrated into the daily total values. During the entire measurement period, the daily global radiation and PAR ranged from 0.5 to $30.1 \mathrm{MJ} \mathrm{m}^{-2} \mathrm{~d}^{-1}$ and 1.2 to $58.6 \mathrm{~mol}$ photon $\mathrm{m}^{-2} \mathrm{~d}^{-1}$, respectively (Fig. 3a). The 


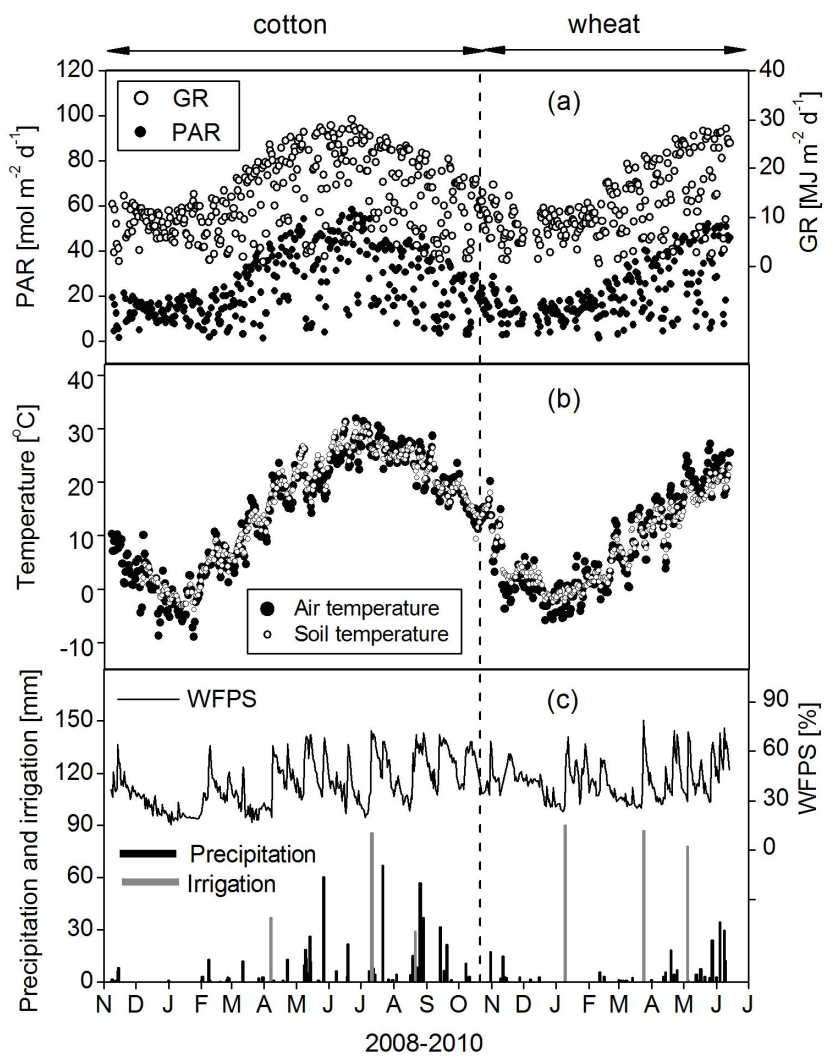

Fig. 3. (a) The daily cumulative global radiation (GR) and photosynthesis active radiation (PAR), (b) the daily mean air temperature and soil temperature at a depth of $5 \mathrm{~cm}$, (c) the daily precipitation, the water amount of each irrigation event and the daily mean soil moisture (water-filled pore space, i.e. WFPS) at depths of $0-6 \mathrm{~cm}$ during the entire measurement period.

daily mean air and soil ( $5 \mathrm{~cm}$ depth) temperature ranged from -9.0 to $31.9^{\circ} \mathrm{C}$ and -3.8 to $31.2^{\circ} \mathrm{C}$, respectively (Fig. 3b). The total precipitation was $525.8 \mathrm{~mm}$ and $214.3 \mathrm{~mm}$ during the cotton and wheat measurement periods, respectively. The rainfall mainly occurred in late spring and summer (Fig. 3c). There were six irrigation events, which supplied a total of $150.5 \mathrm{~mm}$ and $253.7 \mathrm{~mm}$ of water to the cotton and wheat fields, respectively (Fig. 3c). The soil water content was closely related to rainfall and irrigation events. The daily means of soil moisture in WFPS varied widely, from 16 to $72 \%$ (mean: $39 \%$ ) and 23 to $79 \%$ (mean: $42 \%$ ) during the cotton and wheat measurement periods, respectively (Fig. 3c).

The chamber enclosure caused significant differences between air and soil temperatures inside and air and soil temperatures outside the automatic chambers during the oneminute sampling period $(p<0.01)$. The inside air temperatures were higher by $1.9^{\circ} \mathrm{C}$ (wheat) and $2.3{ }^{\circ} \mathrm{C}$ (cotton) on average in the daytime, and lower by $-1.0^{\circ} \mathrm{C}$ (wheat) and $-0.8^{\circ} \mathrm{C}$ (cotton) on average in the nighttime. The largest daytime differences occurred in May (cotton) and June (wheat). The soil temperatures in the chamber were found to be $0.7^{\circ} \mathrm{C}$ (wheat) or 1.3 (cotton) higher in the daytime and $0.6^{\circ} \mathrm{C}$ higher in the nighttime (both cotton and wheat). The observed temperature differences were applied to correct the raw AC fluxes.

The weekly measured aboveground biomass $(\mathrm{AB}$, in $\mathrm{g} \mathrm{m}^{-2}$ ) in the ambient area was fitted to the day after germination $(x$, in $\mathrm{d})$ using the logistic growth curve (Eq. 12). The fitting parameters $p_{1}\left(\mathrm{~g} \mathrm{~m}^{-2}\right), p_{2}$ and $p_{3}$ were 1266 , 104 , and 4, respectively, for the cotton $\left(n=14, R^{2}=0.995\right.$, $p=0.000$ ), and 1608,177 , and 11 , respectively, for the wheat $\left(n=24, R^{2}=0.993, p=0.000\right)$.

$$
\mathrm{AB}=p_{1}-\frac{p_{1}}{1+\left(x / p_{2}\right)^{p_{3}}}
$$

\subsection{Eddy covariance NEE}

In the cotton field, we obtained 7137 valid half-hourly EC fluxes (Fig. 4a), resulting in data coverage of $41 \%$. The fluxes ranged from -0.508 to $0.230 \mathrm{mg} \mathrm{C} \mathrm{m}^{-2} \mathrm{~s}^{-1}$ and displayed a clear seasonal variation pattern with small but continuously positive values in the fallow period (from November 2008 to mid-April 2009) and much larger negative (daytime) or positive (nighttime) values during the vegetation period. During the fallow period, the NEE was equal to the $\mathrm{CO}_{2}$ efflux from soil respiration, with a mean flux of $0.017 \pm 0.015\left( \pm 1\right.$ standard deviation, SD) $\mathrm{mg} \mathrm{C} \mathrm{m}^{-2} \mathrm{~s}^{-1}$. Nearly $84 \%$ of the variation in NEE during this period can be explained by temperature $(p<0.01)$. In response to the germination of cotton, the half-hourly NEE started to display a weak diurnal variation in late April, with lower values in the daytime and higher values in the nighttime. This diurnal pattern became more noticeable during the vegetation period due to enhanced daytime photosynthesis and nighttime respiration. The daily NEE fluxes ranged from -9.39 to $3.78 \mathrm{~g} \mathrm{C} \mathrm{m}^{-2} \mathrm{~d}^{-1}$. The minimum daily flux was observed on 23 July 2009. The EC measurement in the cotton field resulted in an annual NEE of $-40 \mathrm{~g} \mathrm{C} \mathrm{m}^{-2} \mathrm{yr}^{-1}$ and a cumulative NEE of $190,-75,-151$ and $-4 \mathrm{~g} \mathrm{C} \mathrm{m}^{-2}$ during the $\mathrm{C} 1, \mathrm{C} 2, \mathrm{C} 3$ and $\mathrm{C} 4$ periods, respectively (Table 1).

In the wheat field, we obtained 5172 valid half-hourly EC fluxes (Fig. 4b). The data coverage was $46 \%$. These fluxes ranged from -0.641 to $0.175 \mathrm{mg} \mathrm{C} \mathrm{m}^{-2} \mathrm{~s}^{-1}$ and showed a significant seasonal variation pattern. The wheat germinated after a rainfall that occurred on 31 October 2009. Afterwards, we observed diurnal variation of NEE in November and December, which showed slight negative fluxes in the daytime. From mid-December 2009 to early February 2010, the wheat experienced winter dormancy due to freezing. During this period, the average daytime and nighttime half-hourly fluxes were -0.004 and $0.009 \mathrm{mg} \mathrm{C} \mathrm{m}^{-2} \mathrm{~s}^{-1}$, respectively. As the soil became warmer in the spring, the NEE magnitude gradually increased (Fig. 4a). The daily NEE fluxes of the wheat field ranged from -11.69 to $5.74 \mathrm{~g} \mathrm{C} \mathrm{m}^{-2} \mathrm{~d}^{-1}$ (Fig. 5b). The 


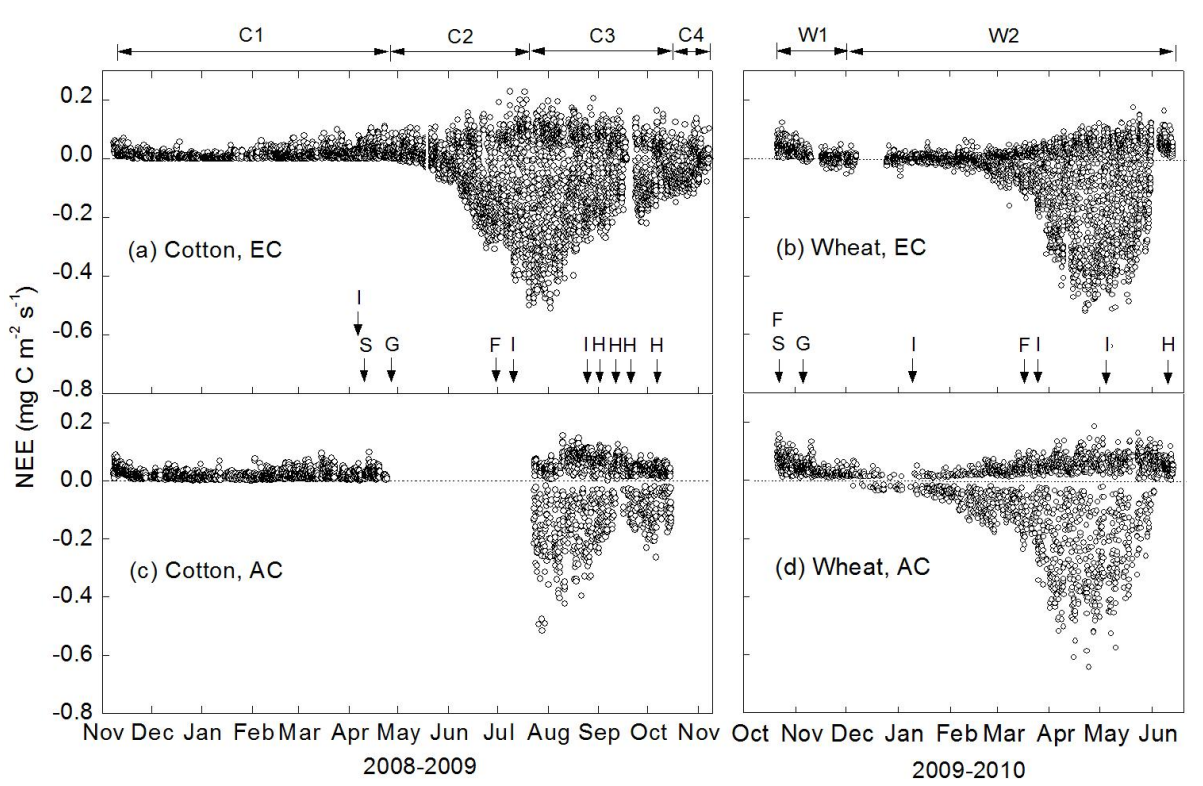

Fig. 4. Half-hourly net ecosystem exchange (NEE) measured using the eddy covariance (EC) and automatic static chamber (AC) techniques in the cotton and wheat fields. The arrows with "S", "G", "F", "I," and "H" indicate the dates of sewing, germination, fertilization, irrigation and harvest, respectively.

Table 1. The cumulative NEEs $\left(\mathrm{g} \mathrm{C} \mathrm{m}^{-2}\right)$ and the relative uncertainties $(\%)$ derived from the measurements using the automatic chamber (AC) and eddy covariance (EC) techniques.

\begin{tabular}{lccc}
\hline Period $^{\mathrm{a}}$ & $\mathrm{AC}^{\mathrm{b}}$ & $\mathrm{EC}$ & $\mathrm{D}^{\mathrm{e}}$ \\
\hline Cotton & & $190(-25 \%,-32 \sim-18 \%)$ & $2.1 \%$ \\
C1 & $194(-19 \%,-25 \sim-12 \%)^{\mathrm{c}}$ & $-75(-25 \%,-31 \sim-19 \%)$ & \\
C2 & $-104^{\mathrm{d}}(-21 \%,-27 \sim-14 \%)$ & $-151(-25 \%,-31 \sim-19 \%)$ & $-9.0 \%$ \\
C3 & $-138(-21 \%,-27 \sim-14 \%)$ & $-15 \%)$ & \\
C4 & $6^{\mathrm{d}}(-21 \%,-27 \sim-14 \%)$ & $-4(-25 \%,-31 \sim-19 \%)$ & \\
Annual & $-42(-20 \%,-26 \sim-13 \%)$ & $-40(-25 \%,-31 \sim-19 \%)$ & \\
\hline Wheat & $134(15 \%, 8 \sim 22 \%)$ & $67(-25 \%,-33 \sim-17 \%)$ & \\
W1 & $-339(-4 \%,-11 \sim 3 \%)$ & $-317(-25 \%,-31 \sim-19 \%)$ & $6.7 \%$ \\
W2 & & & \\
\hline
\end{tabular}

a C1, C2, C3 and C4 represent the periods 8 November 2008-24 April 2009, 25 April-22 July 2009,

23 July-15 October 2009, and 16 October-7 November 2009 of the cotton field. W1 and W2 represent the periods of

21 October-30 November 2009 and 1 December 2009-13 June 2010 of the wheat field.

$\mathrm{b}$ Estimates of $\mathrm{AC}$ were the averages of the four chambers.

${ }^{c}$ Figures outside the parentheses represent the cumulative fluxes, and those inside represent the mean and the range

of the relative uncertainties.

${ }^{\mathrm{d}}$ Estimates fully derived from gap-filling.

e Differences between the cumulative AC and EC fluxes, calculated following (AC-EC)/(AC/2+EC/2) $\times 100 \%$.

minimum daily flux was observed on 28 April 2010 and the maximum on 8 June 2010.

The cumulative NEE of the entire wheat measurement period was estimated at $-251 \mathrm{~g} \mathrm{C} \mathrm{m}^{-2}$ based on the EC data. During the periods $\mathrm{W} 1$ and $\mathrm{W} 2$, the cumulative estimates were 67 and $-317 \mathrm{~g} \mathrm{C} \mathrm{m}^{-2}$, respectively (Table 1).

\subsection{Chamber NEE}

Using the AC system, we obtained 2571 and 2932 valid NEE fluxes in the cotton and the wheat fields, respectively, which corresponded to data coverage of $42 \%$ for the cotton and $52 \%$ for the wheat. During the fallow period, the temperature correction reduced the $\mathrm{AC}$ fluxes by $6 \%$ in the daytime but had very little influence on the nighttime fluxes. During the vegetation periods, the overlap effect of the correction on temperature and PAR increased the AC fluxes by $1 \%$ (cotton) 

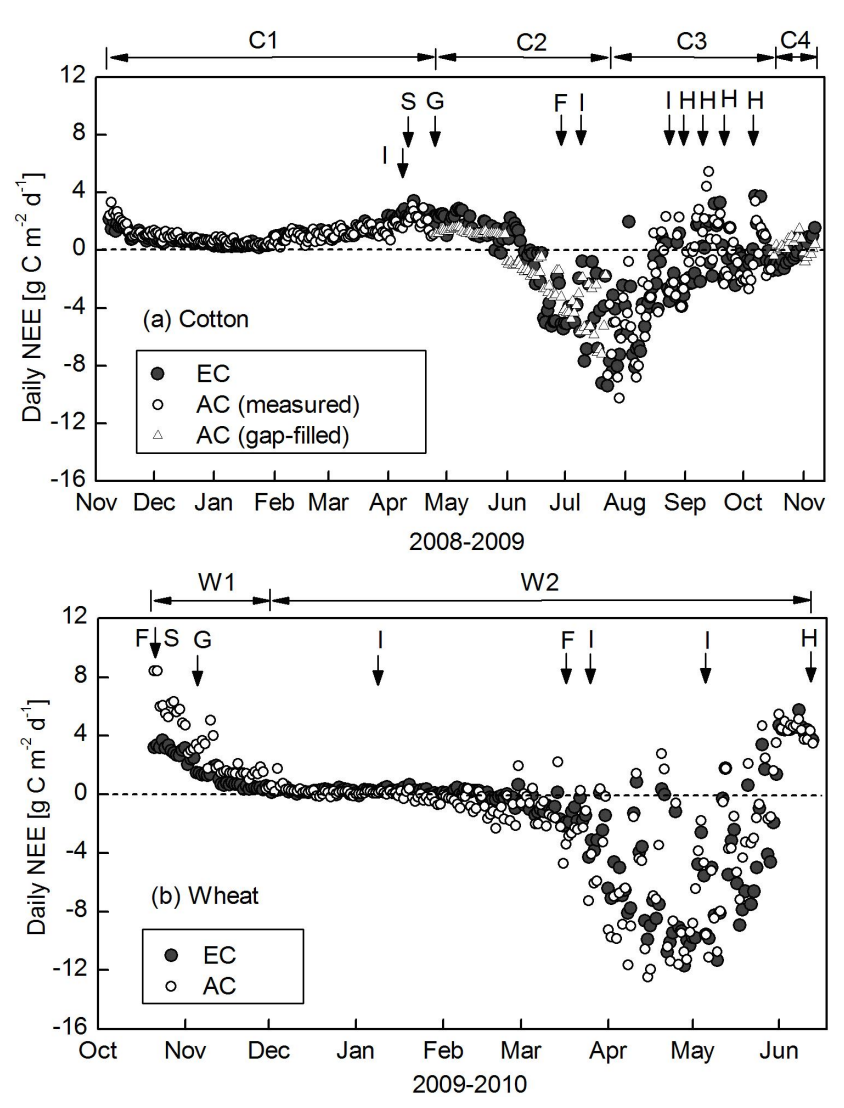

Fig. 5. Daily NEE fluxes measured using the eddy covariance (EC) and automatic static chamber (AC) techniques in the (a) cotton and (b) wheat fields.

or $7 \%$ (wheat) in the nighttime and by $15 \%$ (cotton) or $11 \%$ (wheat) in the daytime.

The gap period $\mathrm{C} 2$ separated the cotton measurement period into fallow $(\mathrm{C} 1)$ and vegetation $(\mathrm{C} 3)$ periods. The halfhourly AC fluxes ranged from 0.002 to $0.099 \mathrm{mg} \mathrm{C} \mathrm{m}^{-2} \mathrm{~s}^{-1}$ during $\mathrm{C} 1$ and from -0.516 to $0.157 \mathrm{mg} \mathrm{C} \mathrm{m}^{-2} \mathrm{~s}^{-1}$ during C3 (Fig. 4c). The daily NEE of period C1 ranged from 0.23 to $3.32 \mathrm{~g} \mathrm{C} \mathrm{m}^{-2} \mathrm{~d}^{-1}$ (Fig. 5a) and resulted in an average cumulative flux of $194 \mathrm{~g} \mathrm{C} \mathrm{m}^{-2}$. The daily fluxes of period $\mathrm{C} 3$ varied between -10.27 and $5.46 \mathrm{~g} \mathrm{C} \mathrm{m}^{-2} \mathrm{~d}^{-1}$ (Fig. 5a) and the cumulative NEE was $-138 \mathrm{~g} \mathrm{C} \mathrm{m}^{-2}$ on average (Table 1).

The half-hourly AC fluxes from the wheat field ranged from -0.644 to $0.187 \mathrm{mg} \mathrm{C} \mathrm{m}^{-2} \mathrm{~s}^{-1}$ (Fig. 4d). Significant positive NEE fluxes were measured in the first five weeks. In December and January, the data coverage was relatively low $(<20 \%)$. The cold weather had inhibited both the $\mathrm{CO}_{2}$ emission from respiration and the uptake by photosynthesis. The fluxes were usually at marginal levels during these two months. By contrast, during the remainder of the time during the wheat season, the data rejection rate was much smaller. The daily NEE fluxes varied between -12.46 and $8.40 \mathrm{~g} \mathrm{C} \mathrm{m}^{-2} \mathrm{~d}^{-1}$ (Fig. 5b). The cumulative NEE from the $\mathrm{AC}$ measurements was estimated to be $-205 \mathrm{~g} \mathrm{C} \mathrm{m}^{-2}$ for the entire wheat measurement period, and $134 \mathrm{~g} \mathrm{C} \mathrm{m}^{-2}$ and $-339 \mathrm{~g} \mathrm{C} \mathrm{m}^{-2}$ for the periods of $\mathrm{W} 1$ and $\mathrm{W} 2$, respectively (Table 1).

\subsection{Comparison between chamber and eddy covariance NEE}

In both the cotton and the wheat field, the half-hourly NEE fluxes measured by the EC and AC methods, as well as their daily estimates, displayed similar seasonal variation patterns (Figs. 4-5).

Figure 6 shows significant zero-intercept linear regressions $(p<0.001)$ between the half-hourly fluxes simultaneously measured by the two methods during the measurement periods on the cotton (Fig. 6a) and the wheat (Fig. 6b) fields. The slopes indicate that the AC fluxes were 0.78 and 1.06 times the size of the EC fluxes from the two fields, respectively. Data from the W1 period were not included in the comparison, because the difference between the tillage depth at the chamber locations and the tillage depth in the ambient area might have contributed to the significant difference in the NEE fluxes during this period (AC higher by $100 \%$, $p<0.001$ ).

The comparison of the daily NEE fluxes between the two methods showed better agreement (Fig. 6c-d). The significant correlations $(p<0.001)$ indicate that the daily AC fluxes were on average 0.94 (cotton) and 1.00 (wheat) times the daily EC fluxes. This finding suggests that the AC-based AMEG system can yield NEE estimates in good agreement with those from the EC techniques.

During the periods in which there were comparable field conditions and both instruments performed normally, the differences in the cumulative NEE between the two methods ranged from -9.0 to $6.7 \%$, with a mean value of $0.1 \%$ (Table 1).

\section{Discussions}

\subsection{Uncertainties in eddy covariance NEE}

The random uncertainty in the EC flux mainly originated in the statistical errors associated with the EC method (Moncrieff et al., 1996). It decreased with increasing data set size. During the periods $\mathrm{C} 1, \mathrm{C} 2, \mathrm{C} 3, \mathrm{C} 4, \mathrm{~W} 1$ and $\mathrm{W} 2$, this uncertainty was estimated at $2.2 \%, 0.9 \%, 0.7 \%, 0.8 \%, 3.3 \%$ and $0.6 \%$, respectively. For the annual cotton period and the entire wheat period, it decreased to $0.6 \%$ and $0.5 \%$, respectively.

The systematic uncertainties in the EC fluxes included the flux losses due to insufficient coverage of the high or low frequency contribution to the turbulent fluxes (Moore, 1986), the biases caused by fluctuations of temperature and water vapor (Webb et al., 1980), and the flux underestimation due to insufficient turbulence development (Foken et al., 2004). These errors were reduced as much as possible by 

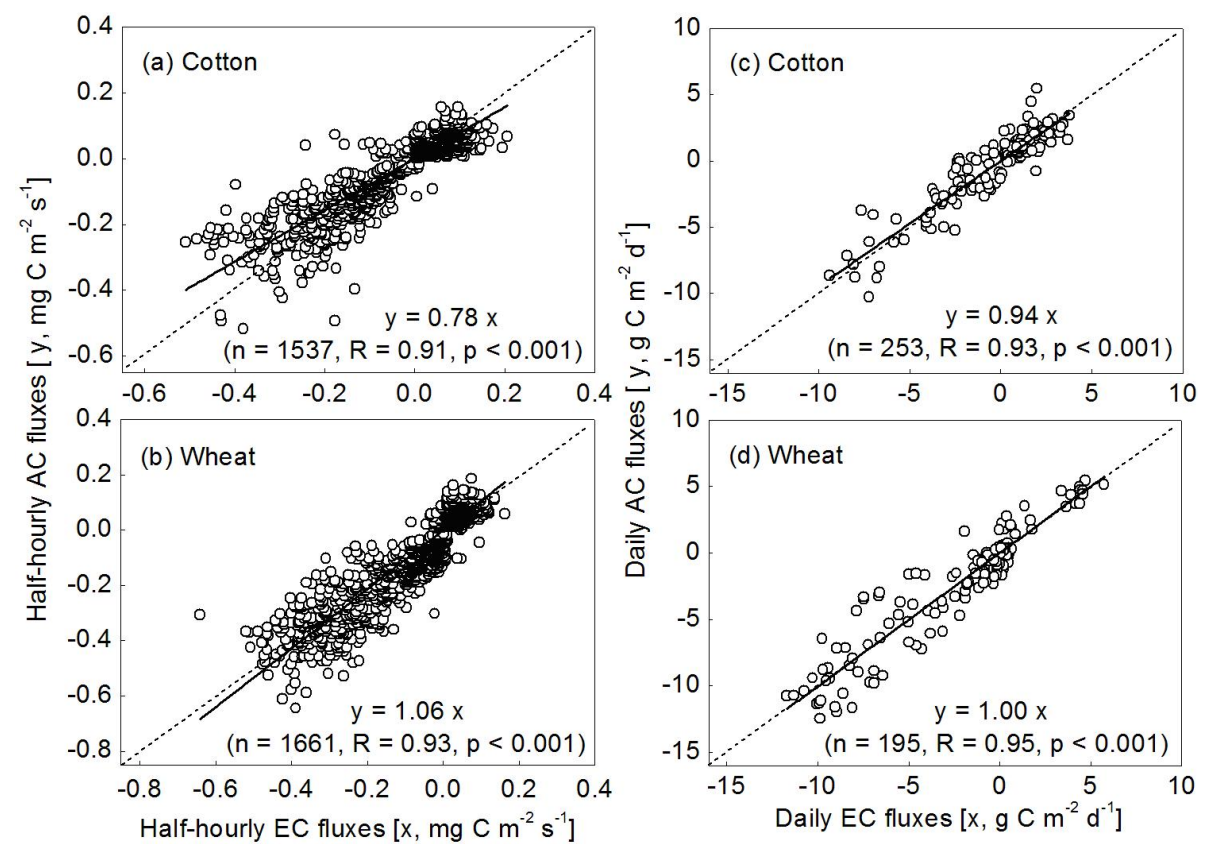

Fig. 6. Comparison of the half-hourly $(\mathbf{a}, \mathbf{b})$ and daily $(\mathbf{c}, \mathbf{d})$ NEE fluxes between the automatic chamber (AC) and eddy covariance (EC) techniques. (a) and (c) present the data of periods C1 and C3. (b) and (d) show the data of period W2. Definitions of periods C1, C3 and W2 are given in the footnotes of Table 1 as well as in the text.

applying the corrections and quality controls as described in Sect. 2.2.2. However, the systematic errors may still remain due to incorrect application of these post-field processing treatments (Moncrieff et al., 1996) and other potential factors, such as the bias due to the surface heating effect of the open-path analyzer (Burba et al., 2008). In our study, the LI-7500 analyzers were mounted at an angle $\left(45^{\circ}\right)$ from the vertical. Unfortunately, the techniques currently available for correcting the surface heating effect are only suitable for vertical sensors, and thus would overestimate the bias for the titled sensors. Besides, directly applying this correction seems unwarranted at present because the results of the correction varied greatly among different experimental sites (Burba et al., 2008; Wohlfahrt et al., 2008; Haslwanter et al., 2009). For these reasons, we assumed that the self-heating effect was of minimal importance in our case. In previous studies (e.g., Sottocornola and Kiely, 2005; Mauder et al., 2013), the lack of surface energy balance was considered as an indicator for estimating the systematic errors in EC fluxes. Considering that this parameter was not available at our site, we accessed the reports in the literature on energy balance deficits at agricultural sites (Foken et al., 2010; Lei and Yang, 2010) and made a rough estimate of $-30 \sim-20 \%$ (mean: $-25 \%$ ) for the systematic uncertainty in the NEE fluxes at our site. This underestimation was not used to correct the EC fluxes.

Combining the random and systematic components, we obtained the total relative uncertainties of the cumulative NEEs. They were estimated at $-25 \%(-32 \sim-18 \%)$ during period $\mathrm{C} 1,-25 \%(-31 \sim-19 \%)$ during periods $\mathrm{C} 2$,
$\mathrm{C} 3$ and $\mathrm{C} 4,-25 \%(-33 \sim-17 \%)$ during period $\mathrm{W} 1$, and $-25 \%(-31 \sim-19 \%)$ during period W2. During the annual period of the cotton field, the total uncertainty was estimated at $-25 \%(-31 \sim-19 \%)$.

\subsection{Uncertainties in automatic chamber NEE}

The random uncertainties in the half-hourly AC fluxes were mainly introduced by instrumental detection noise. They were estimated at \pm 0.002 and $\pm 0.004 \mathrm{mg} \mathrm{C} \mathrm{m}^{-2} \mathrm{~s}^{-1}$ for the 45- and 90-cm chambers, respectively. According to Eq. (10), the random uncertainties in the daily NEE estimates were $8 \%, 7 \%, 8 \%$ and $7 \%$ during the periods $\mathrm{C} 1$, $\mathrm{C} 3$, W1 and W2, respectively. The random errors in the cumulative NEE of these four periods were then estimated at $0.6 \%, 0.8 \%, 1.3 \%$ and $0.5 \%$, respectively.

Because chamber deployment can lead to a nonlinear increase or decrease of $\mathrm{CO}_{2}$ concentration within the chamber headspace over time (Hutchinson et al., 2000; Kutzbach et al., 2007; Pedersen et al., 2010, etc.), the nonlinear regression method was involved in flux calculation in this study. However, significant nonlinearity could not always be detected, which could lead to flux underestimation. This detection failure rate was $48 \%$ for the cotton and $56 \%$ for the wheat. Meanwhile, we compared the fluxes calculated with the nonlinear and the linear procedures using the data from the nonlinear cases. This revealed an underestimation of $22 \%$ by the linear method, which was within the range (4-40\%) reported in previous studies (Kutzbach et al., 2007; 
Schneider et al., 2009; Jassal et al., 2012). Consequently, the systematic underestimation due to detection failure for significant nonlinearity was estimated at $-11 \% \sim 0$ (median: $-5 \%$ ) and $-12 \% \sim 0$ (median: $-6 \%$ ) for the cotton and wheat fields, respectively.

Spatial heterogeneity is always a problem for AC measurement, as the measured fluxes only represent the limited area where the chambers are placed; therefore, it can be another source of systematic uncertainty. During the fallow period, this error was determined by comparing the mean EC fluxes from the automatic chamber directions $\left(30-60^{\circ}\right.$ and $120-150^{\circ}$ for the cotton and wheat, respectively) with those from all wind directions, and the differences were $-13 \%$ and $21 \%$ for the cotton and wheat fields, respectively. During the vegetation period, we performed the same approach only using the nighttime fluxes, as the large variation of daytime NEE fluxes might bias this analysis. The results showed that the fluxes from the chamber direction area were $15 \%$ lower (cotton) and $2 \%$ higher (wheat) than the fluxes from all wind directions. The biomass difference between inside and outside the chambers due to chamber effect was negligible as the measurement locations were changed frequently during the growing periods of the cotton and wheat.

The total relative uncertainties in the cumulative NEEs were obtained by summing up the random and systematic parts. They were estimated at $-19 \%(-25 \sim-12 \%)$ during period $\mathrm{C} 1,-21 \%(-27 \sim-14 \%)$ during period $\mathrm{C} 3,15 \%$ $(8 \sim 22 \%)$ during period $\mathrm{W} 1$, and $-4 \%(-11 \sim 3 \%)$ during period W2 (Table 1). On the timescale of these periods, the uncertainties in the chamber-based NEE were predominantly systematic, and the random uncertainties were negligible. The flux uncertainties of gaps $\mathrm{C} 2$ and $\mathrm{C} 4$ were treated as if roughly the same as those of period C3 (Table 1), because periods $\mathrm{C} 2-\mathrm{C} 4$ were all during the growing stage of the cotton and their sources of error were considered to be the same. Therefore, the uncertainties were dominated by the systematic part, as the random part had become very small due to the large number of data sets.

\subsection{Comparison between chamber and eddy covariance NEE}

In this study, the simultaneous NEE measurements with EC and $\mathrm{AC}$ techniques covered nearly eight months in the two fields. The data sets enabled comparisons between the two methods under a wide range of environmental conditions.

On average, the daily NEE fluxes derived from the two methods were in agreement with each other (Fig. 6c-d). By comparing the cumulative NEEs of individual periods, we found the greatest difference during period W1, for which the AC result was $100 \%$ higher (Table 1). This large discrepancy can most likely be attributed to the difference between the tillage depth at the chamber locations $(20 \mathrm{~cm})$ and in the ambient field $(5 \mathrm{~cm})$, as deeper tillage might have stimulated more $\mathrm{CO}_{2}$ emissions from soil respiration (Bauer et al., 2006;
Moraru et al., 2012) (Fig. 5b). For this reason, the period W1 data were omitted from further comparisons between the two techniques. In contrast to the data for W1, the cumulative NEE of AC and EC showed much smaller differences during periods $\mathrm{C} 1, \mathrm{C} 3$ and $\mathrm{W} 2$ (Table 1). We compared the cumulative NEEs for the three periods using a zero-intercept linear regression and found a significant relationship between the two methods (slope $=1.04, n=3, R=0.997, p<0.05$ ). The slope indicates that the AC estimate was $4 \%$ higher on average, suggesting that the AC technique was able to provide NEE estimates comparable to those derived from the EC measurements, particularly on seasonal or annual timescales. This level of difference is similar to that reported by Laine et al. (2006) but much smaller than those reported by Dore et al. (2003) and Fox et al. (2008).

The cumulative $\mathrm{AC}$ fluxes of the gap periods $\mathrm{C} 2$ and $\mathrm{C} 4$ were roughly estimated to be -104 and $6 \mathrm{~g} \mathrm{C} \mathrm{m}^{-2}$, respectively, following the gap-filling procedure described in Sect. 2.3.3. Therefore, we were able to obtain an annual NEE estimate of $-42 \mathrm{~g} \mathrm{C} \mathrm{m}^{-2} \mathrm{yr}^{-1}$ for the cotton field. This result matched with the estimate $\left(-40 \mathrm{~g} \mathrm{C} \mathrm{m}^{-2}\right)$ derived from the EC measurements very well (Table 1). When the cumulative NEEs of periods $\mathrm{C} 2$ and $\mathrm{C} 4$ were included in the zero-intercept linear regression, we again observed that there was a significant correlation between the two methods (slope $=1.05, n=5, R=0.996, p=0.000$ ). This finding further indicates that the AMEG system can provide NEE estimates similar to those of the EC measurements.

We compared the cumulative NEEs of periods $\mathrm{C} 1, \mathrm{C} 3$, and W2 after they were corrected by the values of mean uncertainty in Table 1 and found that the two methods were still linearly correlated, but with a decreased slope of 0.86 . This difference suggested that the energy balance deficit $(25 \%)$ adapted from the literature may have been an overestimate of the negative systematic biases of the EC fluxes, provided that the errors in the AC fluxes were accurately estimated. Therefore, simultaneous measurement of the lack of energy balance closure is necessary to provide supporting evidence. On the other hand, more research should be conducted to develop direct methods for estimating systematic uncertainties for EC measurements.

\section{Conclusions}

The net ecosystem exchange (NEE) fluxes of carbon dioxide $\left(\mathrm{CO}_{2}\right)$ were measured using static, transparent automatic chamber (AC) and eddy covariance (EC) techniques simultaneously. The measurements were conducted in a cotton field for a year and in a winter wheat field for an entire cropping season. Based on a comparison between the NEE fluxes measured using the two techniques, the following conclusions can be drawn. There is good agreement between the NEE measured using the $\mathrm{AC}$ and EC techniques at half-hourly, daily, seasonal and annual timescales, as long as the biases 
due to the modification of headspace temperature and radiation are corrected in data processing, and as long as onsite operation (such as alternation of chamber locations) is frequently carried out to minimize chamber effects on the growth of the enclosed plants. Such data agreement has confirmed that the $\mathrm{AC}$ technique is a necessary alternative to the EC technique, if plant heights are suitable for chamber operation. These results also demonstrate the satisfactory performance of AMEG (an AC system designed for monitoring fluxes of multiple carbon and nitrogen trace gases) for measuring NEE fluxes of short-plant croplands.

Acknowledgements. This study was supported by the Ministry of Science and Technology of China (project 2012CB417100), the Chinese Academy of Sciences (projects XDA05020100, GJHZ1213 and YZ200909), the National Natural Science Foundation of China (projects 41021004 and 40711130636) and the Academy of Finland (projects 124094, 256082, 1127756 postdoctoral project, 137352 and 141518 ICOS, 1118615 Finnish Centre of Excellence, EU projects ICOS, GHG-Europe and InGOS). We appreciate Shixie Meng, Bingwen Hao, and Tingyu Wang for their technical support with the field measurements. We also thank Stefan Metzger, Ivan Mammarella, and Üllar Rannik for their generous help with data processing and analysis.

Edited by: P. Stoy

\section{References}

Aurela, M., Laurila, T., and Tuovinen, J.-P.: Annual $\mathrm{CO}_{2}$ balance of a subarctic fen in northern Europe: Importance of the wintertime efflux, J. Geophys. Res., 107, 4607, doi:10.1029/2002JD002055, 2002.

Baldocchi, D. D.: Assessing the eddy covariance technique for evaluating carbon dioxide exchange rates of ecosystems: past, present and future, Glob. Change Biol., 9, 479-492, 2003.

Bauer, P. J., Frederick, J. R., Novak, J. M., and Hunt, P. G.: Soil CO flux from a norfolk loamy sand after 25 years of conventional and conservation tillage, Soil Till. Res., 90, 205-211, 2006.

Burba, G. G., McDermitt, D. K., Grelle, A., Anderson, D. J., and $\mathrm{Xu}, \mathrm{L}$.: Addressing the influence of instrument surface heat exchange on the measurement of $\mathrm{CO}_{2}$ flux from open-path gas analyzers, Glob. Change Biol., 14, 1854-1876, 2008.

Burkart, S., Manderscheid, R., and Weigel, H. J.: Design and performance of a portable gas exchange chamber system for $\mathrm{CO}_{2}$ - and $\mathrm{H}_{2} \mathrm{O}$-flux measurements in crop canopies, Environ. Exp. Bot., 61, 25-34, 2007.

Chapin III, F. S., Woodwell, G. M., Randerson, J. T., Rastetter, E. B., Lovett, G. M., Baldocchi, D. D., Clark, D. A., Harmon, M. E., Schimel, D. S., Valentini, R., Wirth, C., Aber, J. D., Cole, J. J., Goulden, M. L., Harden, J. W., Heimann, M., Howarth, R. W., Matson, P. A., McGuire, A. D., Melillo, J. M., Mooney, H. A., Neff, J. C., Houghton, R. A., Pace, M. L., Ryan, M. G., Running, S. W., Sala, O. E., Schlesinger, W. H., and Schulze E.-D.: Reconciling carbon-cycle concepts, terminology, and methods, Ecosystems, 9, 1041-1050, 2006.
Davidson, E. A., Savage, K., Verchot, L. V., and Navarro, R.: Minimizing artifacts and biases in chamber-based measurements of soil respiration, Agr. Forest Meteorol., 113, 21-37, 2002.

Dore, S., Hymus, G. J., Johnson, D. P., Hinkle, C. R., Valentini, R., and Drake, B. G.: Cross validation of open-top chamber and eddy covariance measurements of ecosystem $\mathrm{CO}_{2}$ exchange in a Florida scrub-oak ecosystem, Glob. Change Biol., 9, 84-95, 2003.

Falge, E., Baldocchi, D., Olson, R., Anthoni, P., Aubinet, M., Bernhofer, C., Burba, G., Ceulemans, R., Clement, R., Dolman, H., Granier, A., Gross, P., Grunwald, T., Hollinger, D., Jensen, N. O., Katul, G., Keronen, P., Kowalski, A., Lai, C. T., Law, B. E., Meyers, T., Moncrieff, H., Moors, E., Munger, J. W., Pilegaard, K., Rannik, U., Rebmann, C., Suyker, A., Tenhunen, J., Tu, K., Verma, S., Vesala, T., Wilson, K., and Wofsy, S.: Gap filling strategies for defensible annual sums of net ecosystem exchange, Agr. Forest Meteorol., 107, 43-69, 2001.

Foken, T. and Wichura, B.: Tools for quality assessment of surfacebased flux measurements, Agr. Forest Meteorol., 78, 83-105, 1996.

Foken, T., Mauder, M., Liebethal, C., Wimmer, F., Beyrich, F., Leps, J. P., Raasch, S., DeBruin, H. A. R., Meijninger, W. M. L., and Bange, J.: Energy balance closure for the LITFASS-2003 experiment, Theor. Appl. Climatol., 101, 149-160, 2010.

Fox, A. M., Huntley, B., Lloyd, C. R., Williams, M., and Baxter, R.: Net ecosystem exchange over heterogeneous Arctic tundra: Scaling between chamber and eddy covariance measurements, Global Biogeochem. Cy., 22, GB2027, doi:10.1029/2007GB003027, 2008.

Goulden, M. L., Munger, J. W., Fan, S. M., Daube, B. C., and Wofsy, S. C.: Exchange of carbon dioxide by a deciduous forest: response to interannual climate variability, Science, 271, 15761578, 1996.

Haslwanter, A., Hammerle, A., and Wohlfahrt, G.: Open-path vs. close-path eddy covariance measurements of the net ecosystem carbon dioxide and water vapor exchange: a long-term perspective, Agr. Forest Meteorol., 149, 291-302, 2009.

Hollinger, D. Y., Kelliher, F. M., Byers, J. N., Hunt, J. E., McSeveny, T. M., and Weir, P. L.: Carbon dioxide exchange between an undisturbed old-growth temperate forest and the atmosphere, Ecology, 75, 134-150, 1994.

Horst, T. W. and Weil, J. C.: How Far Is Far Enough? : The fetch requirements for micrometeorological measurement of surface fluxes, J. Atmos. Ocean. Tech. 11, 1018-1025, 1994.

Hutchinson, G. L., Livingston, G. P., Healy, R. W., and Striegl, R. G.: Chamber measurement of surface-atmosphere trace gas exchange: Numerical evaluation of dependence on soil, interfacial layer, and source/sink properties, J. Geophys. Res., 105, 8865$8875,2000$.

Intergovernmental Panel of Climate Change (IPCC): IPCC Guidelines for National Greenhouse Gas Inventories, Prepared by the National Greenhouse Gas Inventories Programme, edited by: Eggleston, H. S., Buendia, L., Miwa, K., Ngara, T., and Tanabe, K., IGES, Japan, 2006.

Jassal, R. S., Black, T. A., Nesic Z., and Gaumont-Guay, D.: Using non-steady-state automated chamber systems for making continuous long-term measurements of soil $\mathrm{CO}_{2}$ efflux in forest ecosystems, Agr. Forest Meteorol., 161, 57-65, 2012. 
Kaimal, J. C. and Finnigan, J. J.: Atmospheric Boundary Layer Flows, Oxford University Press, Oxford, 289 pp., 1994.

Kutzbach, L., Schneider, J., Sachs, T., Giebels, M., Nykänen, H., Shurpali, N. J., Martikainen, P. J., Alm, J., and Wilmking, $\mathrm{M}$.: $\mathrm{CO}_{2}$ flux determination by closed-chamber methods can be seriously biased by inappropriate application of linear regression, Biogeosciences, 4, 1005-1025, doi:10.5194/bg4-1005-2007, 2007.

Lafleur, P. M., McCaughey, J. H., Joiner, D. W., Bartlett, P. A., and Jelinski, D. E.: Seasonal trends in energy, water, and carbon dioxide fluxes at a northern boreal wetland, J. Geophys. Res., 102, 29009-29020, 1997.

Laine, A., Sottocornola, M., Kiely, G., Byrne, K. A., Wilson, D., and Tuittila, E. S.: Estimating net ecosystem exchange in a patterned ecosystem: Example from blanket bog, Agr. Forest Meteorol., 138, 231-243, 2006.

Langensiepen, M., Kupisch, M., Wijk, M. T. van, and Ewert, F.: Analyzing transient closed chamber effects on canopy gas exchange for optimizing flux calculation timing, Agr. Forest Meteorol., 164, 61-70, 2012.

Lee, X., Massman, W., and Law, B.: Handbook of Micrometeorology: A Guide for Surface Flux Measurement and Analysis, Kluwer Academic Publishers, Dordrecht, the Netherlands, 2004.

Lei, H. M. and Yang, D. W.: Seasonal and interannual variations in carbon dioxide exchange over a cropland in the North China Plain, Glob. Change Biol., 16, 2944-2957, 2010.

Liu, C., Zheng, X., Zhou, Z., Han, S., Wang, Y., Wang, K., Liang, W., Li, M., Chen, D., and Yang, Z.: Nitrous oxide and nitric oxide emissions from an irrigated cotton field in Northern China, Plant Soil, 332, 123-134, 2010.

Liu, C., Wang, K., Meng, S., Zheng, X., Zhou, Z., Han, S., Chen, D., and Yang, Z.: Effects of irrigation, fertilization and crop straw management on nitrous oxide and nitric oxide emissions from a wheat-maize rotation field in northern China, Agr. Ecosyst. Environ., 140, 226-233, 2011.

Liu, C., Wang, K., and Zheng, X.: Responses of $\mathrm{N}_{2} \mathrm{O}$ and $\mathrm{CH}_{4}$ fluxes to fertilizer nitrogen addition rates in an irrigated wheatmaize cropping system in northern China, Biogeosciences, 9, 839-850, doi:10.5194/bg-9-839-2012, 2012.

Livingston, G. P. and Hutchinson, G. L.: Enclosure-based measurement of trace gas exchange: applications and sources of error, in: Biogenic Trace Gases: Measuring Emissions from Soil and Water, edited by: Matson, P. A. and Harriss, R. C. , Blackwell Scientific Publications, Oxford, 14-51, 1995.

Lloyd, J. and Taylor, J. A.: On the Temperature-Dependence of Soil Respiration, Funct. Ecol., 8, 315-323, 1994.

Maljanen, M., Martikainen, P. J., Walden, J., and Silvola, J.: $\mathrm{CO}_{2}$ exchange in an organic field growing barley or grass in eastern Finland, Glob. Change Biol., 7, 679-692, 2001.

Mauder, M., Cuntz, M., Drüe, C., Graf, A., Rebmann, C., Schmida, H. P., Schmidtd, M., and Steinbrechera, R.: A strategy for quality and uncertainty assessment of long-term eddy-covariance measurements, Agr. Forest Meteoeol., 169, 122-135, 2013.

Miyata, A., Leuning, R., Denmead, O. W., Kim, J., and Harazano, Y.: Carbon dioxide and methane fluxes from an intermittently flooded paddy field, Agr. Forest Meteorol., 102, 287-303, 2000.
Moncrieff, J. B., Malhi, Y., and Leuning, R.: The propagation of errors in long-term measurements of land-atmosphere fluxes of carbon and water, Glob. Change Biol., 2, 231-240, 1996.

Moore, C. J.: Frequency-Response Corrections for EddyCorrelation Systems, Bound.-Lay. Meteorol., 37, 17-35, 1986.

Moraru, P. I. and Rusu, T. : Effect of tillage systems on soil moisture, soil temperature, soil respiration and production of wheat, maize and soybean crops, J. Food Agric. Environ., 10, 445-448, 2012.

Pedersen, A. R., Petersen, S. O., and Schelde, K.: A comprehensive approach to soil-atmosphere trace-gas flux estimation with static chambers, Eur. J. Soil Sci., 61, 888-902, 2010.

Schneider, J., Kutzbach, L., Schulz, S., and Wilmking, M.: Overestimation of $\mathrm{CO}_{2}$ respiration fluxes by the closed chamber method in low-turbulence nighttime conditions, J. Geophys. Res., 114, G03005, doi:10.1029/2008JG000909, 2009.

Sottocornola, M. and Kiely, G.: An Atlantic blanket bog is a modest $\mathrm{CO}_{2}$ sink, Geophys. Res. Lett., 32, L23804., doi:10.1029/2005GL024731, 2005.

Steduto, P., Cetinkökü, Ö., Albrizio, R., and Kanber, R.: Automated closed-system canopy-chamber for continuous field-crop monitoring of $\mathrm{CO}_{2}$ and $\mathrm{H}_{2} \mathrm{O}$ fluxes, Agr. Forest Meteorol., 111, 171186, 2002.

Vickers, D. and Mahrt, L.: Quality control and flux sampling problems for tower and aircraft data, J. Atmos. Ocean Tech., 14, 512526, 1997.

Wang, K., Zheng, X., Pihlatie, M., Vesala, T., Liu, C., Haapanala, S., Mammarella, I., Rannik, Ü., and Liu, H.: Comparison between static chamber and tunable diode laser-based eddy covariance techniques for measuring nitrous oxide fluxes from a cotton field, Agr. Forest Meteorol., 171-172, 9-19, 2013.

Webb, E. K., Pearman, G. I., and Leuning, R.: Correction of Flux Measurements for Density Effects Due to Heat and Water-Vapor Transfer, Q. J. Roy. Meteor. Soc., 106, 85-100, 1980.

Welles, J. M., Demetriades-Shah, T. H., and McDermitt D. K.: Considerations for measuring ground $\mathrm{CO}_{2}$ effluxes with chambers, Chem. Geol., 177, 3-13, 2001.

Wohlfahrt, G., Fenstermaker, L. F., and Arnone III., J. A.: Large annual net ecosystem $\mathrm{CO}_{2}$ uptake of a Mojave desert ecosystem, Glob. Change Biol., 14, 1475-1487, 2008.

Zheng, X., Xie, B., Liu, C., Zhou, Z., Yao, Z., Wang, Y. H., Wang, Y. L., Yang, L., Zhu, J., Huang, Y., and Butterbach-Bahl, K.: Quantifying net ecosystem carbon dioxide exchange (NEE) of a shortplant cropland with intermittent chamber measurements, Global Biogeochem. Cy., 22, GB3031, doi:10.1029/2007GB003104, 2008a.

Zheng, X., Mei, B., Wang, Y., Xie, B., Wang, Y., Dong, H., Xu, H., Chen, G., Cai, Z., Yue, J., Gu, J., Su, F., Zou, J., and Zhu, J.: Quantification of $\mathrm{N}_{2} \mathrm{O}$ fluxes from soil-plant systems may be biased by the applied gas chromatograph methodology, Plant Soil, 311, 211-314, 2008b. 